\title{
Diversifying Design Imaginations
}

\author{
Phoebe Sengers \\ Cornell University \\ Ithaca, NY USA \\ sengers@cs.cornell.edu
}

\begin{abstract}
The act of designing technologies does not simply create functionality; it also offers possibilities for action, ways of looking at the world, and modes through which we can relate to one another. How we design technologies reflects what we value; who we think is important, and in what ways; which places, people and possibilities are in our imaginations, and which are not.
\end{abstract}

Current ways of designing technologies frequently narrow these possibilities, in two ways. The first is that technology design is dominated by a narrow demographic: predominantly white and Asian, white collar, highly educated, urban. These designers' ways of imagining new technological worlds are shaped by the worlds they themselves know and value, which are only a small slice of global ways of being. The second is that even as technology design is being increasingly engaged in around the world by and for people outside this demographic, local adaptations are frequently judged and limited by what makes sense from the perspective of Silicon Valley and other urban high-tech centers.

Supporting the rich diversity of human experience requires explicitly identifying and appreciating values and experiences outside of mainstream technology design logics.

\section{ACM Classification Keywords}

K.4.2. Social Issues; H.5.2. User Interfaces

\section{Author Keywords}

Interaction design; speculative futures; values in design; diversity; postcolonial computing; ethnography

\section{BIOGRAPHY}

Phoebe Sengers is an Associate Professor at Cornell in Information Science and Science \& Technology Studies, where she leads the Culturally Embedded Computing group. Her work integrates ethnographic and historical analysis of the social implications of technology with design methods to suggest alternative future possibilities. Her group explores rural, working-class and global South experiences of technologies, traces the emerging entanglements between people and data, and uses design to speculate about alternative pasts and futures.

Sengers led the Cornell campus of the Intel Science \& Technology Center for Social Computing, has been a Fulbright Fellow, a Fellow in the Cornell Society for the Humanities, and a Public Voices Fellow, and received an NSF CAREER award. She holds an interdisciplinary PhD in Artificial Intelligence and Cultural Theory from Carnegie Mellon University.



\section{ACKNOWLEDGEMENTS}

This work was supported by the US National Science Foundation under grants 1217685 and 1526155 , by the Intel Science \& Technology Center for Social Computing, by the Cornell Institute for Social Sciences, and by Memorial University of Newfoundland \& Labrador.
Permission to make digital or hard copies of part or all of this work for personal or classroom use is granted without fee provided that copies are not made or distributed for profit or commercial advantage and that copies bear this notice and the full citation on the first page. Copyrights for third-party components of this work must be honored. For all other uses, contact the owner/author(s).

DIS 2018, June 9-13, 2018, Hong Kong.

Copyright is held by the author/owner(s).

ACM ISBN 978-1-4503-5198-0/18/06.

DOI: https://doi.org/10.1145/3196709.3196823 